Bariatric Surgery

\title{
A longitudinal study of the antilipolytic effect of insulin in women following bariatric surgery
}

\author{
Kelvin Ho Man Kwok (iD ${ }^{1,2}$, Daniel P. Andersson (iD ${ }^{2}$, Mikael Rydén (iD ${ }^{2}$ and Peter Arner (iD ${ }^{\circledR}$
}

(c) The Author(s) 2021

Insulin resistance of glucose utilization is fully restored following BMI normalization after bariatric surgery. We investigated if this also pertains to insulin-induced effects on fatty acid handling. Forty-three women with obesity (OB) were investigated before and 2 years after Roux-en-Y gastric by-pass when BMI was $<30 \mathrm{~kg} / \mathrm{m}^{2}$ (PO) and compared with 26 never obese women (NO). The Adipo-IR index was used as measure of insulin antilipolytic sensitivity. Changes (delta) in circulating glycerol and fatty acid levels during hyperinsulinemic euglycemic clamp represented the insulin maximum antilipolytic effect. Overall fatty acid utilization was reflected by delta fatty acids minus $3 \times$ delta glycerol. Adipo-IR was higher in OB than in NO and PO $(p<0.0001)$, the latter two groups having similar values. Insulin lowered glycerol levels by about $70 \%$ in all groups, but delta glycerol was $30 \%$ larger in PO than in NO $(p=0.04)$. Delta adds and adds utilization were similar in all groups. We conclude that women with obesity, whose BMI is normalized after bariatric surgery, have improved maximum in vivo antilipolytic effect of insulin above expected in absolute but not relative terms as regards glycerol changes, while the handling of circulating fatty acids is changed to the normal state.

International Journal of Obesity (2021) 45:2675-2678; https://doi.org/10.1038/s41366-021-00914-2

\section{INTRODUCTION}

Insulin inhibits lipolysis in fat cells through spare receptors [1]. Therefore, adipose insulin resistance at early signal steps is mirrored by the half maximum effective concentration (insulin sensitivity), while resistance at distal steps at very high hormone concentrations reflects maximum action (responsiveness). Subjects with obesity or overweight display decreased sensitivity but normal responsiveness for the antilipolytic effect in fat cells [2]. Insulin resistance may also involve additional fatty acid metabolic events [3].

In post-obesity, in vivo insulin-induced glucose metabolism is completely normalized [4]. Whether the same pertains to antilipolysis and/or fatty acid utilization is unknown although reduction of BMI from about 43 to $32 \mathrm{~kg} / \mathrm{m}^{2}$ normalized the antilipolytic effect of insulin in vitro [5].

We presently investigated the effects of insulin on circulating fatty acids in vivo. Women with obesity were investigated before (OB) and 2 years after gastric by-pass when they had attained a post-obese state (PO). They were compared with never obese women (NO). Changes in circulating fatty acids and glycerol during hyperinsulinemic euglycemic clamp measured insulin responsiveness. Antilipolytic insulin sensitivity was estimated by the so-called Adipo-IR index [6], which correlates strongly with antilipolytic sensitivity in vivo and in vitro $[7,8]$.

\section{MATERIAL AND METHODS}

The patients were from a longitudinal study (NCT01727245) of Roux-en-Y bypass (RYGB) surgery for obesity. This sub-study examined 43 women before and 2 years after RYGB when they reached a $P O$ state $\left(B M l<30 \mathrm{~kg} / \mathrm{m}^{2}\right)$. For comparison, 26 never obese healthy control women (NO) were recruited. None had severe chronic disorder, diabetes, or regularly used pain killers. Twelve had hypertension which remained in five patients at follow-up. Postoperative dietary instructions were given as described [4]. The study was approved by the regional ethics committee in Stockholm and informed written consent was obtained.

Examinations were performed in the morning after an overnight fast. The menstrual cycle was not considered as it does not seem to influence lipolysis or adipocyte insulin action. Venous blood was used for routine clinical chemistry measures. Adipo-IR was calculated from serum insulin and fatty acid values [8]. There is no consensus on how to measure the antilipolytic action of insulin in vivo [6]. We performed a 2-h standard highdose insulin clamp investigation for responsiveness at 10 a.m. as described [4]. Glucose disposal rate was determined during the last hour ( $M$-value). The insulin effect was calculated as differences (delta) in serum glycerol or fatty acids values between the end $(115 \mathrm{~min})$ and start $(-5 \mathrm{~min})$ of clamp. We also calculated $\%$ inhibition of glycerol levels. The overall fatty acid utilization was reflected as delta $(\mu \mathrm{mol} / \mathrm{l})$ fatty acids minus $3 \times$ delta glycerol. The breakdown of one triglyceride molecule during lipolysis generates one glycerol and three fatty acids. The validity of the calculation rests on several assumptions. Glycerol is not significantly metabolized by fat cells but mainly by the liver. In the fasting state, glycerol can to some extent be produced by hydrolysis of circulating triglycerides [9]. There is no report that insulin influences liver glycerol metabolism such as

${ }^{1}$ Department of Biosciences and Nutrition, Karolinska Institutet, Stockholm, Sweden. ${ }^{2}$ Department of Medicine (H7), Karolinska Institutet at Karolinska University Hospital, Stockholm, Sweden. ${ }^{凶}$ email: peter.arner@ki.se 
gluconeogenesis or triglyceride assembly or hydrolysis of circulating triglycerides. Therefore, delta glycerol mainly reflects lipolysis changes. Fatty acids are produced and re-esterified by fat cells, oxidized mainly in skeletal muscle, used by the liver in the production of triglycerides in very low-density lipoproteins (VLDL-TG). They are also trapped within the adipose tissue extracellular space. Oxidation and VLDL-TG production are inhibited in vivo by insulin [10,11]. Re-esterification and fatty acid trapping are stimulated by insulin [12, 13]. Our protocol does not distinguish between these forms of fatty acid utilization. We assumed that the distribution volumes for glycerol and fatty acids were the same in all groups and that elimination rates of glycerol and fatty acids were in steady state during the last hour of clamp as for glucose disposal rate.

Glycerol was determined by a specific bioluminescence method [14] and insulin by ELISA (Mercodia, Sweden). Fatty acids were measured using a specific colorimetric kit (FUJIFILM Wako Chemicals Europe $\mathrm{GmbH}$, Germany). Some fatty acid values were below detection limit and treated as zero.

Values are mean \pm SD in text and tables and as described in legend to figures. Delta glycerol and fatty acids were primary outcome variables. NO was compared with $\mathrm{OB}$ and $\mathrm{PO}$ by unpaired $t$-test. $\mathrm{OB}$ and $\mathrm{PO}$ were compared by paired $t$-test and analysis of covariance (ANCOVA). We compared changes in antilipolysis with changes in clinical variables after RYGB using linear regression. All statistical tests were two-tailed with $p<$ 0.05 as statistically significant.

\section{RESULTS}

Clinical data are in Table 1. Body weight decreased by $33 \pm 7 \%$ following RYGB $(p<0.0001)$. OB displayed expected clinical abnormalities which normalized after RYGB to values comparable with NO, except for slightly lower insulin in PO. Adipo-IR values were increased in $\mathrm{OB}$ and decreased to NO levels in PO.

There was a rapid steady-state elevation of insulin values during the clamp (Fig. S1A) and a swift decrease in glycerol levels, which leveled off at about one-third of the initial values (Fig. S1B). Thus, insulin was not able to clear the circulation of glycerol. In contrast, circulating fatty acid levels decreased to almost zero in all three conditions (Fig. S1C).

Absolute values for glycerol are recorded in Fig. 1A. At $-5 \mathrm{~min}$, they were similar in $\mathrm{OB}$ and $\mathrm{NO}$ but higher in $\mathrm{PO}$ than $\mathrm{NO}(p=$ 0.015). At $115 \mathrm{~min}$ of clamp, $\mathrm{OB}$ and $\mathrm{PO}$ had similar values but higher than in NO $(p \leq 0.015)$. Changes in glycerol (delta) were calculated. Delta glycerol was comparable in NO and OB but $30 \%$ greater in $\mathrm{PO}$ than in $\mathrm{NO}(p=0.04)$. The difference remained after correction for -5 min glycerol value by ANCOVA ( $F=4.1 ; p=0.048$ ). However, in relative terms inhibition of glycerol levels by insulin was similar in NO, OB, and PO $(73 \pm 8 \%, 67 \pm 8 \%$, and $71 \pm 7 \%$, respectively). For delta fatty acids (Fig. 1B) or fatty acid utilization (Fig. 1C), no significant differences between groups were recorded. Antihypertension therapy did not influence the results. No relationship was observed between changes in C-reactive protein, $M$-value, or \% body weight decrease and delta glycerol following RYGB.

\section{DISCUSSION}

Adipose insulin resistance may develop before other metabolic alterations and directly contribute to impaired insulin action in skeletal muscle and liver [15]. It is apparent that obesity has different impact on glycerol and fatty acid handling by insulin.

We studied insulin action indirectly. Changes in glycerol and fatty acid levels represented maximum insulin action and Adipo-IR reflected insulin sensitivity. Therefore, the interpretation of the data rests on several assumptions regarding appearance and removal of glycerol and fatty acids from the circulation. Insulin has additional effects on fatty acid handling besides antilipolysis as thoroughly discussed in "Material and methods". For technical reasons it was not possible to directly examine these events (oxidation, VLDL-TG production, adipose trapping). Insulin may also have hitherto unrecognized effects on glycerol metabolism. Therefore, it is not known if some of these actions of insulin are differentially altered after RYGB treatment. However, by comparing changes in fatty acids and glycerol during the clamp we could get a reflection of total fatty acid utilization, which was not altered in obesity or changed after RYGB treatment. Furthermore, insulin almost fully suppressed circulating fatty acid levels in all conditions, suggesting that the maximum action of insulin on fatty acid handling is not influenced by obesity. On the other hand, the sensitivity of antilipolysis and thereby insulin sensitivity of fatty acid handling (Adipo-IR) is clearly reduced in obesity but fully normalized in the post-obese state. In absolute terms the maximum antilipolytic effect (delta glycerol) is not altered by obesity but increased by $30 \%$ in the post-obese state compared with the never obese state. However, in relative terms this maximum effect was similar in all three conditions (about $70 \%$ inhibition).

Our results relate to lipolysis in the morning after an overnight fast when both Adipo-IR (at 8 a.m.) and clamp (at 10 a.m.) were performed. Diurnal measures of lipolysis show that the rate is highest by then and not related to insulin status [16]. We only examined women and sex influences lipid metabolism [17, 18]. Therefore, we cannot extrapolate our findings to men. We also do not know the molecular mechanism(s) behind the findings. It is

Table 1. Clinical characteristics in women.

\begin{tabular}{|c|c|c|c|c|c|c|}
\hline & \multirow[b]{2}{*}{ NO $(n=26)$} & \multicolumn{5}{|c|}{$p$ value } \\
\hline & & OB $(n=43)$ & PO $(n=43)$ & NO vs. OB & OB vs. PO & NO vs. PO \\
\hline Age (years) & $44 \pm 12$ & $43 \pm 10$ & $45 \pm 10$ & 0.64 & $<0.0001$ & 0.74 \\
\hline BMI $\left(\mathrm{kg} / \mathrm{m}^{2}\right)$ & $24.4 \pm 2.6$ & $38.4 \pm 3.0$ & $25.6 \pm 2.7$ & $<0.0001$ & $<0.0001$ & 0.12 \\
\hline Waist circumference $(\mathrm{cm})$ & $88 \pm 10$ & $120 \pm 7$ & $90 \pm 7$ & $<0.0001$ & $<0.0001$ & 0.28 \\
\hline Waist-to-hip ratio & $0.87 \pm 0.07$ & $0.98 \pm 0.07$ & $0.90 \pm 0.06$ & $<0.0001$ & $<0.0001$ & 0.19 \\
\hline$M$-value $\mathrm{mg} / \mathrm{kg} / \mathrm{min}$ & $12.1 \pm 2.6$ & $9.9 \pm 3.4$ & $11.7 \pm 2.5$ & 0.004 & $<0.0001$ & 0.57 \\
\hline fP C-reactive protein, $\mathrm{mg} / \mathrm{l}$ & $1.9 \pm 3.2$ & $6.0 \pm 7.1$ & $0.7 \pm 1.0$ & 0.0007 & $<0.0001$ & 0.30 \\
\hline fP-glucose (mmol/l) & $5.1 \pm 0.4$ & $5.4 \pm 1.0$ & $5.2 \pm 0.5$ & 0.13 & 0.12 & 0.33 \\
\hline fP-triglycerides $(\mathrm{mmol} / \mathrm{l})$ & $0.89 \pm 0.39$ & $1.33 \pm 0.53$ & $0.81 \pm 0.32$ & 0.0004 & $<0.0001$ & 0.40 \\
\hline Adipo-IR, units & $3.7 \pm 2.6$ & $9.1 \pm 4.8$ & $2.9 \pm 1.9$ & $<0.0001$ & $<0.0001$ & 0.35 \\
\hline
\end{tabular}

Values are given as mean \pm SD. They were compared by paired (OB vs. PO) or unpaired (NO vs. OB and PO) $t$-test. $M$-value was related to lean body mass. $N O$ never obese, $O B$ obese, $P O$ post-obese, $f S$ fasting serum, $f P$ fasting plasma. 

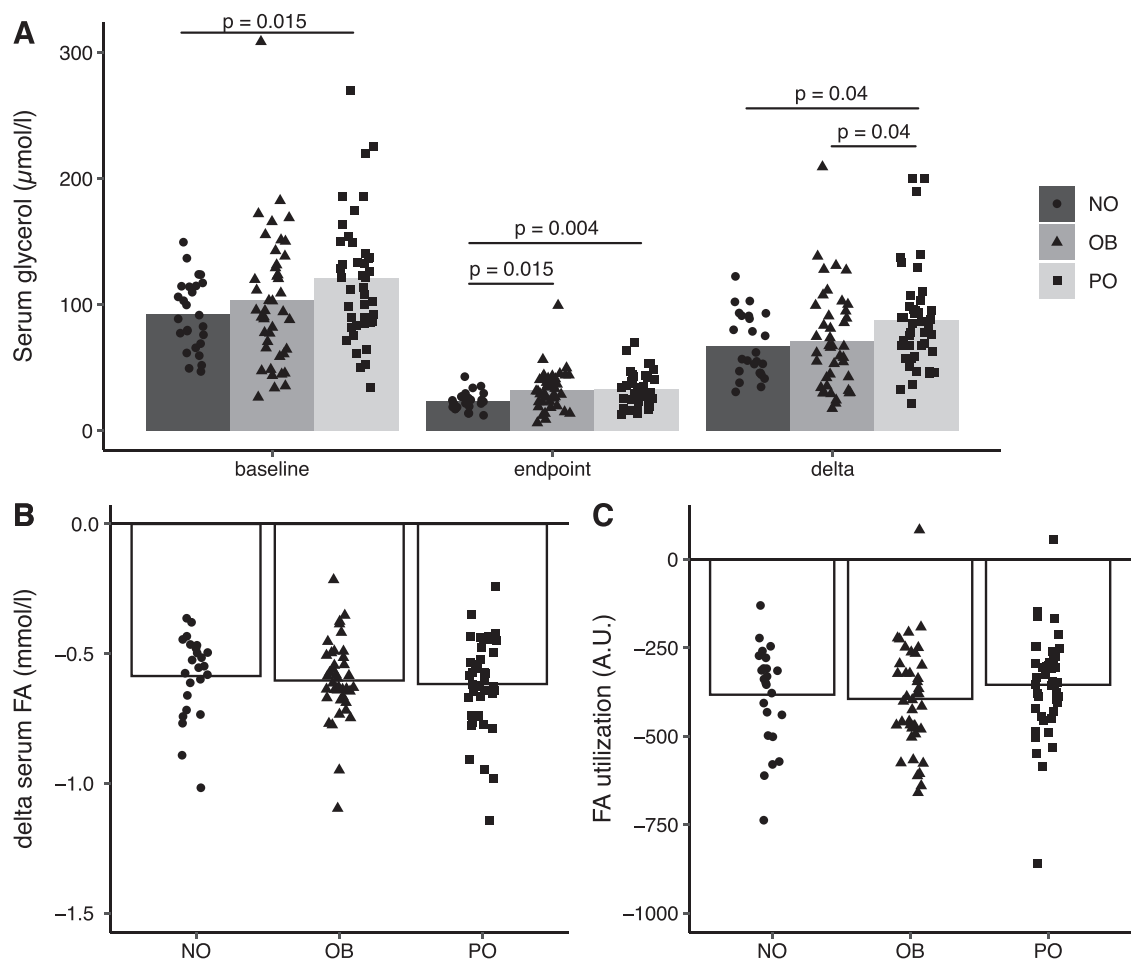

Fig. 1 Findings on serum glycerol and fatty acids (FA) during clamp. A is absolute glycerol levels at -5 min (baseline) and 115 min (endpoint) of clamp as well as delta values (levels at $-5 \mathrm{~min}$ subtracted by the value at $115 \mathrm{~min}$ ). B is delta for fatty acid levels (115-min values subtracted from $-5 \mathrm{~min}$ value, $\mathbf{C}$ is delta for fatty acid re-utilization calculated as in B. Values are mean and individual. Women before (OB, obese state) and after (PO, post-obese state) bariatric surgery were compared by paired $t$-test. Never obese women (NO) were compared with $\mathrm{OB}$ and $\mathrm{PO}$ by unpaired $t$-test. Only significant results are shown $(p<0.05)$. The mean $\pm \mathrm{SD}$ values for delta glycerol $(\mu \mathrm{moles} / \mathrm{l})$ were $67 \pm 25$, $71 \pm 40$, and $87 \pm 41$ in NO, OB, and PO, respectively.

unlikely that the observed effects are explained by the surgical treatment as bariatric surgery and conservative weight-reducing therapy have similar effects on metabolic outcome [19].

Altogether, we propose the following model for insulin action in vivo on glycerol and fatty acids in obesity. In OB, antilipolytic sensitivity, but not effect responsiveness, is decreased implying that fatty acid levels can be almost completely suppressed by high levels of insulin. In PO the sensitivity of antilipolysis is normalized. The absolute maximum effect is increased above the normal level and might be of importance for lower energy expenditure and lipid oxidation rates reported in formerly obese persons [20]. However, the relative maximum antilipolytic effect is not influenced by obesity or weigh reduction $(70 \%$ decrease of starting glycerol level). The maximum effect of insulin on fatty acid handling appears not to be influenced by body weight status.

In summary, long-term body weight reduction to a non-obese state leads to enhanced antilipolytic effect of insulin in absolute but not relative terms when glycerol levels are investigated. Nevertheless fatty acid utilization is normal.

\section{REFERENCES}

1. Kahn CR. Insulin resistance, insulin insensitivity, and insulin unresponsiveness: a necessary distinction. Metabolism. 1978;27:1893-902.

2. Ryden M, Petrus P, Andersson DP, Medina-Gomez G, Escasany E, Corrales Cordon $P$, et al. Insulin action is severely impaired in adipocytes of apparently healthy overweight and obese subjects. J Intern Med. 2019;285:578-88.

3. Wakil SJ, Abu-Elheiga LA. Fatty acid metabolism: target for metabolic syndrome. J Lipid Res. 2009;50:S138-43.

4. Andersson DP, Dahlman I, Eriksson Hogling D, Backdahl J, Toft E, Qvisth V, et al. Improved metabolism and body composition beyond normal levels following gastric bypass surgery: a longitudinal study. J Intern Med. 2019;285:92-101.
5. Lofgren P, Hoffstedt J, Naslund E, Wiren M, Arner P. Prospective and controlled studies of the actions of insulin and catecholamine in fat cells of obese women following weight reduction. Diabetologia. 2005;48:2334-42.

6. Sondergaard E, Jensen MD. Quantification of adipose tissue insulin sensitivity. J Investig Med. 2016;64:989-91.

7. Sondergaard E, Espinosa De Ycaza AE, Morgan-Bathke M, Jensen MD. How to measure adipose tissue insulin sensitivity. J Clin Endocrinol Metab. 2017;102:1193-9.

8. Ryden M, Andersson DP, Arner P. Usefulness of surrogate markers to determine insulin action in fat cells. Int J Obes. 2020;44:2436-43.

9. Jensen MD, Chandramouli V, Schumann WC, Ekberg K, Previs SF, Gupta S, et al. Sources of blood glycerol during fasting. Am J Physiol Endocrinol Metab. 2001;281:E998-1004.

10. Sidossis LS, Wolfe RR. Glucose and insulin-induced inhibition of fatty acid oxidation: the glucose-fatty acid cycle reversed. Am J Physiol. 1996;270: E733-8.

11. Lewis GF, Steiner G. Acute effects of insulin in the control of VLDL production in humans. Implications for the insulin-resistant state. Diabetes Care. 1996;19:390-3.

12. Van Harmelen V, Reynisdottir S, Cianflone K, Degerman E, Hoffstedt J, Nilsell K, et al. Mechanisms involved in the regulation of free fatty acid release from isolated human fat cells by acylation-stimulating protein and insulin. J Biol Chem. 1999:274:18243-51.

13. Kalant D, Phelis S, Fielding BA, Frayn KN, Cianflone K, Sniderman AD. Increased postprandial fatty acid trapping in subcutaneous adipose tissue in obese women. J Lipid Res. 2000;41:1963-8.

14. Hellmer J, Arner P, Lundin A. Automatic luminometric kinetic assay of glycerol for lipolysis studies. Anal Biochem. 1989;177:132-7.

15. Ferrannini E, Barrett EJ, Bevilacqua S, DeFronzo RA. Effect of fatty acids on glucose production and utilization in man. J Clin Invest. 1983;72:1737-47.

16. Hagstrom-Toft $E$, Bolinder J, Ungerstedt $U$, Arner P. A circadian rhythm in lipid mobilization which is altered in IDDM. Diabetologia. 1997;40:1070-8.

17. Blaak E. Gender differences in fat metabolism. Curr Opin Clin Nutr Metab Care. 2001:4:499-502

18. Santosa $S$, Jensen MD. The sexual dimorphism of lipid kinetics in humans. Front Endocrinol (Lausanne). 2015;6:103. 
19. Yoshino M, Kayser BD, Yoshino J, Stein Rl, Reeds D, Eagon JC, et al. Effects of diet versus gastric bypass on metabolic function in diabetes. $\mathrm{N}$ Engl J Med. 2020;383:721-32.

20. Wyatt HR, Grunwald GK, Seagle HM, Klem ML, McGuire MT, Wing RR, et al. Resting energy expenditure in reduced-obese subjects in the National Weight Control Registry. Am J Clin Nutr. 1999;69:1189-93.

\section{AUTHOR CONTRIBUTIONS}

PA designed the study and wrote together with KHMK the first version of the paper. KHMK measured fatty acids and glycerol and analyzed the data together with PA. MR and DPA performed clamp experiments and participated together with PA and KHMK in the interpretation of data. All authors contributed to further writing and accepted the final version of the paper.

\section{FUNDING}

This study was supported by grants from the Swedish Research Council, Novo Nordisk Foundation, CIMED, Knut and Alice Wallenbergs Foundation, Stockholm County Council, Diabetes Research Program at the Karolinska Institutet. KHMK is a recipient of the Novo Nordisk Post-doctoral Fellowship at Karolinska Institutet.

\section{COMPETING INTERESTS}

The authors declare no competing interests.

\section{ADDITIONAL INFORMATION}

Supplementary information The online version contains supplementary material available at https://doi.org/10.1038/s41366-021-00914-2.

Correspondence and requests for materials should be addressed to P.A.

Reprints and permission information is available at http://www.nature.com/ reprints

Publisher's note Springer Nature remains neutral with regard to jurisdictional claims in published maps and institutional affiliations.

(c) (i)

Open Access This article is licensed under a Creative Commons Attribution 4.0 International License, which permits use, sharing, adaptation, distribution and reproduction in any medium or format, as long as you give appropriate credit to the original author(s) and the source, provide a link to the Creative Commons license, and indicate if changes were made. The images or other third party material in this article are included in the article's Creative Commons license, unless indicated otherwise in a credit line to the material. If material is not included in the article's Creative Commons license and your intended use is not permitted by statutory regulation or exceeds the permitted use, you will need to obtain permission directly from the copyright holder. To view a copy of this license, visit http://creativecommons. org/licenses/by/4.0/.

(c) The Author(s) 2021 